\title{
Twarz i inne wyznaczniki dynamiki interakcyjnej w kontekście kulturowym
}

\author{
Ewa Bogdanowska-Jakubowska \\ Uniwersytet Śląski w Katowicach \\ ewa.jakubowska@us.edu.pl
}

\begin{abstract}
Streszczenie
Przedmiotem pracy jest pojęcie twarzy (wizerunku wtasnego jednostki) oraz jego rola $w$ kontaktach międzyludzkich. Społeczne znaczenie twarzy uzależnione jest od kontekstu kulturowego, a w szczególności od wartości dominujących $w$ danej kulturze oraz od charakteru relacji spotecznych tam występujących. Twarz uważana jest za główny wyznacznik dynamiki interakcji spolecznej w kulturach zachodnich. Nie we wszystkich kulturach, jednak, petni ona tak ważna rolę. Celem pracy jest przedstawienie głównych wyznaczników dynamiki interakcyjnej w kulturze anglo-amerykańskiej i polskiej.
\end{abstract}

Słowa kluczowe: twarz, interakcja społeczna, kultura, dynamika interakcyjna

Abstract

Face and Other Determinants of Interactional Dynamics in Cultural Context

The subject of the study is the concept of face (self-image of a person) and its role in interpersonal contacts. The social meaning of face depends on a cultural context, particularly on values that dominate in a culture and on the nature of social relations which occur there. In Western cultures face is regarded as the main indicator of the dynamics of social interaction. It does not play an equally significant role in all cultures, however. The present article aims at presenting the main indicators of interactive dynamics in Anglo-American and Polish cultures.

Keywords: face, politeness, social interaction, culture, interactive dynamics 


\section{Twarz}

Twarz, czyli wizerunek własny, jaki tworzymy kontaktując się z innymi ludźmi, pełni istotną rolę w naszych wzajemnych relacjach. Erving Goffman definiuje ją jako ,pozytywną wartość społeczną przypisywaną osobie w danej sytuacji spotkania, gdy inni przyjmą, że trzyma się ona określonej roli” (1967/2006: 5). Uczeni badający kultury zachodnie, indywidualistyczne, traktują twarz jako czynnik determinujący dynamikę interakcji. Nie wszędzie jednak twarz stanowi jedyną taką siłę. Badacze zachowań społecznych w innych niż zachodnie kulturach twierdzą, że twarz pełni tam zaledwie drugorzędną rolę, a miejsce czynnika determinującego charakter interakcji pełnią inne, istotne dla danej kultury wartości.

Celem pracy jest omówienie charakteru czynników określających dynamikę interakcyjną w kulturze polskiej i amerykańskiej. Porównawczy charakter pracy pociąga za sobą konieczność analizy wielu źródeł. Dlatego w pracy wykorzystałam dane zdobyte przy pomocy introspekcji, wywiadów i obserwacji uczestniczącej. Respondenci uczestniczący w badaniu pochodzą z obu kultur: amerykańskiej (50) i polskiej (60). Wszyscy oni (w wieku 2274 lata) są rodowitymi użytkownikami swojego języka i wywodzą się z podobnych środowisk, mają wykształcenie średnie lub wyższe.

\section{Kontekst kulturowy}

Istnieje relacja między kulturą, jej uczestnikami a obserwowanymi wśród nich zachowaniami. Kultura, kształtując naszą strukturę psychologiczną, wpływa na nasze relacje $\mathbf{z}$ innymi ludźmi i nasze zachowanie wobec nich (Singelis and Brown 1995). Kluczem do zrozumienia mechanizmów rządzących dynamiką interakcyjną jest kultura oraz uwarunkowane nią podejście do wartości społecznych. Kultury nie różnią się, bowiem, pod względem istniejących w nich wartości, lecz tylko pod względem ich miejsca w hierarchii. Wartości tłumaczą zachowania ludzkie i dostarczają wskazówek, jak zachować się w kontaktach z innymi, czym kierować się by uniknąć odrzucenia i zostać zaakceptowanym.

Normy społeczne, w tym normy określające zachowania grzecznościowe, stanowią odzwierciedlenie wartości dominujących w danej kulturze. Normy specyficzne dla danej kultury tworzą porządek społeczny, wyrażany podczas kontaktów międzyludzkich (BargielaChiappini 2003). Istnieją dwa typy zachowań grzecznościowych, uprzejmość normatywna i uprzejmość strategiczna. Uprzejmość normatywna to uprzejmość w tradycyjnym rozumieniu; specyficzna dla danej kultury, określona przez obowiązujące w niej normy i przejawiająca się w użyciu w danej sytuacji określonych wyrażeń grzecznościowych i zwrotów 
adresatywnych. Uprzejmość strategiczna w dużym stopniu ma charakter uniwersalny i uwarunkowana jest celami komunikacyjnymi uczestników interakcji oraz dbałością o twarz (cf. Usami, 2006). To uprzejmość, w rozumieniu Brown i Levinsona (1987), stosowana strategicznie w celu osiągnięcia osobistych celów. Oba typy uprzejmości ze sobą współistnieją w każdej kulturze; różnice kulturowe w zachowaniach grzecznościowych wynikają, między innymi, z dominacji jednego lub drugiego typu.

Kultury można podzielić na (Bargiela-Chiappini 2003):

- kultury społecznie rozwarstwione, gdzie dominuje uprzejmość normatywna, i istnieją inne niż twarz determinanty dynamiki interakcyjnej (np. Japonia, Meksyk, kultura Zuluska w Południowej Afryce),

- kultury, w których liczy się twarz i status społeczny, a uprzejmość normatywna współistnieje z uprzejmością strategiczną (np. Chiny, Korea),

- kultury mniej zhierarchizowane, w których status społeczny nie jest tak istotny, uprzejmość strategiczna przeważa nad uprzejmością normatywną, a twarz pełni bardzo istotną rolę (np. Europa, Stany Zjednoczone).

W kulturach społecznie rozwarstwionych kluczem do zrozumienia zachowań interpersonalnych są inne niż twarz wartości dominujące. W Japonii główną determinantą zachowań społecznych jest wakimae, rodzaj uprzejmości językowej, polegającej na doborze odpowiedniej formy adresatywnej lub wyrażenia, w którym zakodowana jest różnica między pozycją mówiącego, adresata i osoby trzeciej (Ide, 1989). W kulturze meksykańskiej, według Wintilo Garcii (1996), czynnikiem takim jest respeto, czyli szacunek wynikający z postrzeganego, a nie faktycznego statusu jednostki w danej interakcji społecznej. Również w innych kulturach, takich jak kultura Ekwadoru czy kultura rosyjska, szacunek wobec interlokutora, związany z jego statusem społecznym, stanowi główną siłę decydującą o sukcesie danej interakcji społecznej (Bargiela-Chiappini 2003).

\subsection{Twarz jako główny wyznacznik dynamiki interakcyjnej w kulturze anglo- amerykańskiej}

W kulturze amerykańskiej, prototypowej kulturze indywidualistycznej, pomimo dość dużego zhierarchizowania, w relacjach społecznych najistotniejsza jest jednostka. I to jednostka oraz interes jednostki stanowią najwyższą wartość podczas interakcji społecznych. Bez względu na cel komunikacyjny, każdy kontakt z drugim człowiekiem podporządkowany jest twarzy. 
Dbałość o twarz, zarówno własną jak i innych uczestników, jak twierdzi Goffman, jest warunkiem interakcji społecznej (2006: 12):

W normalnych okolicznościach zachowanie twarzy nie jest celem, lecz warunkiem interakcji. Cele, jak wyrabianie sobie twarzy, swobodne wyrażanie głębokich przekonań, udzielanie kompromitujących informacji na temat innych lub rozwiązywanie problemów i wykonywanie zadań, są zazwyczaj realizowane tak, żeby w niczym nie narazić twarzy.

Główne wartości, leżące u podstaw kultury amerykańskiej, to wolność, równość, niezależność oraz dążenie do sukcesu. W kulturze amerykańskiej, każdy człowiek uważany jest za wyjątkową, jedyną w swoim rodzaju jednostkę, która odpowiada za swoje słowa i czyny. Posiada twarz, która stanowi jej wizerunek własny, nakreślony, jak twierdzi Goffman, w kategoriach uznanych atrybutów społecznych. Moje badania (Bogdanowska-Jakubowska 2010) wykazały, że należą do nich przede wszystkim: dobra reputacja, wiarygodność, szacunek dla samego siebie, godność, pozycja społeczna wynikająca z osiągnięć jednostki, wrażenie kompetencji, oraz duma. Twarz amerykańska należy wyłącznie do jednostki, która jest niezależna od innych i świadczy o posiadaniu przez nią wolności wyboru. Autonomia jednostki i jej wyjątkowość decydują o charakterze jej relacji z innymi, a co za tym idzie o jej zachowaniu wobec nich.

To wszystko wpływa na charakter uprzejmości dominującej w kulturze amerykańskiej. Egalitaryzm grzecznościowy, według którego wszyscy uczestnicy interakcji są równi w grzecznościowych prawach i obowiązkach, bez względu na wiek, stanowisko czy inny typ hierarchicznej zależności, sprawia, że zachowanie twarzy stanowi podstawę i punkt odniesienia w każdej sytuacji. Tego typu egalitaryzm najlepiej obrazuje użycie zaimka osobowego w drugiej osobie liczby pojedynczej. Angielski zaimek you, zwany przez Annę Wierzbicką (1991) społecznym zrównywaczem (social equilizer), używany jest w odniesieniu zarówno do osób, które bardzo dobrze znamy i z którymi jesteśmy w zażyłych stosunkach jak i do osób zupełnie nam obcych, do rówieśników i osób, od których dzieli nas różnica pokoleniowa, nam równych jak i tych stojących wyżej od nas w hierarchii społecznej.

Przejawem indywidualizmu w zachowaniach jest ostentacyjne manifestowanie własnych gustów, przyzwyczajeń i prawa do wolności. Zgodnie z zasadami obowiązującymi w kulturze amerykańskiej, wchodząc w interakcje z innymi jednostka skoncentrowana jest głównie na sobie, swoim wizerunku własnym, swoich pragnieniach i potrzebach; druga osoba postrzegana jest także przez pryzmat jej własnych potrzeb i wolności, które trzeba uszanować. 
Pomimo konieczności przestrzegania zasady wzajemności w tym względzie, w kontaktach z innymi, Amerykanie zorientowani są głównie na zachowanie własnej twarzy. W kulturze amerykańskiej, nie istnieją sytuacje, w których twarz stanowiłaby wartość nieistotną. Jak twierdzą Scollon i Wong Scollon (2001: 48, tłum. E. B.-J.), „nie ma komunikacji bez twarzy”.

\subsection{Wyznaczniki dynamiki interakcyjnej w kulturze polskiej}

Do tradycyjnych polskich wartości należą szacunek, rodzina, przyjaźń, zażyłość i wzajemne zobowiązania, gościnność i skromność. Polacy mają silną potrzebę przynależności i akceptacji. Kultury polskiej nie można, jednak, jednoznacznie sklasyfikować jako kolektywistycznej. Indywidualizm nigdy nie był obcy naszej kulturze, w polskiej historii można znaleźć wiele przykładów świadczących o niezależności Polaków i ukochaniu przez nich swobody i wolności. Oprócz tego, przeobrażenia polityczne, gospodarcze i społeczne zachodzące w kraju po roku 1989 sprawiły, że jako kraj i jako wspólnota kulturowa staliśmy się bardziej otwarci na wpływy z zewnątrz, a szczególnie na kulturę amerykańską. Te wpływy zaowocowały wzrostem tendencji indywidualistycznych w codziennych zachowaniach, a głównie w stylu autoprezentacyjnym. Taka mieszanka ukształtowała relacje społeczne i sposoby zachowań w Polsce XXI wieku.

W kulturze polskiej bardzo istotną rolę pełnią różnego rodzaju współzależności. To wpływa na dominujący w niej rodzaj uprzejmości. Uprzejmość normatywna, przejawiająca się w zasadach tradycyjnej polskiej uprzejmości, decyduje o naszym zachowaniu wobec osób dla nas ważnych. Dotychczas w relacjach społecznych przede wszystkim liczyła się opinia innych: to nie wypada, nie uchodzi, co ludzie powiedza, co on/ona sobie o mnie pomyśli. Takie myślenie determinowało poczynania wielu pokoleń Polaków. Obecnie, to się zmienia. Powoli model amerykański zyskuje popularność, szczególnie wśród młodych Polaków. Coraz częściej własny interes wygrywa $z$ interesem zbiorowym i dbałością o rozmówcę. A uprzejmość strategiczna wygrywa z uprzejmością normatywną.

Wyniki badań przeze mnie przeprowadzonych (Bogdanowska-Jakubowska 2010) wskazują na twarz, szacunek i honor jako determinanty dynamiki interakcji społecznych w kulturze polskiej. Szacunek i honor często są utożsamiane z twarzą. Gdy, jednak, zastanowić się nad ich znaczeniem i rolą w relacjach społecznych, można dostrzec istotne między nimi różnice.

W kulturze polskiej pojęcie honoru jest bardzo zbliżone w swoim znaczeniu do pojęcia twarzy. Słowa honor i twarz są częściowymi synonimami. Honor to „poczucie godności 
osobistej, dobre imię, cześć" (Słownik języka polskiego 1978-81), a twarz to „dobre imię, szacunek ludzki” (Kopaliński 1987). Jednak, tylko w pewnych okolicznościach mówimy o utracie honoru czy (nie)honorowym zachowaniu. Mówiąc o kimś honorowy, wystawiamy mu jak najlepszą ocenę, honorowy to prawy, przestrzegający zasad moralnych, postępujący zgodnie z zasadami etyki. Mówiąc o honorze, mamy zawsze na myśli wielkie sprawy i doniosłe czyny. Dlatego też, utrata honoru wydaje się być czymś poważniejszym niż utrata twarzy. Twarz można utracić powodu błędu nielicującego z zajmowaną pozycją, przyłapania na kłamstwie, czy zlekceważenia ze strony ważnych dla jednostki osób. Utratę honoru może spowodować przewinienie bardziej fundamentalnego rodzaju, np. brak odwagi, w sytuacji gdy okazanie jej jest oczekiwane, niespełnienie obietnicy istotnej dla drugiej osoby, czy popełnienie czynu świadczącego o braku zasad moralnych. Patrząc historycznie, honor zawsze zajmował wysoką pozycję w polskiej hierarchii wartości. Obecnie, jednak, honor w ocenie młodych Polaków znacznie stracił na wartości i często traktowany jest jak relikt przeszłości (Bogdanowska-Jakubowska 2010).

Szacunek to jedna $\mathrm{z}$ najważniejszych wartości w naszej kulturze. Według zasad dobrego wychowania, szacunek należny jest przede wszystkim kobietom, osobom starszym, oraz osobom o wyższym niż nasz statusie społecznym. Słowo szacunek (,poważanie, uznanie” (Słownik języka polskiego 1978-1981)) jest również synonimem twarzy. Między szacunkiem a honorem, jednak istnieje istotna różnica - honor jest nam dany, swoim zachowaniem możemy go potwierdzić (zachowanie honorowe), lub przez nasze zachowanie możemy go utracić. Na szacunek, natomiast, trzeba sobie zasłużyć (np. godny szacunku), lub można go utracić. Szacunek może nam być dany lub odebrany przez innych. Mówiąc o honorze myślimy o człowieku i jego czynach; mówiąc o szacunku myślimy o zachowaniu innych wobec niego. Okazywanie szacunku wiąże się z używaniem odpowiednich form adresatywnych, stosowaniem odpowiedniego rejestru językowego i określonych zasadami dobrego wychowania zwrotów grzecznościowych. Przemiany w obyczajowości polskiej, jakie miały miejsce po 1989 roku, wpłynęły na demokratyzację polskiej uprzejmości, polegającą na skracaniu dystansu między partnerami komunikacji (Marcjanik 2002; Antas 2002) i przejętym z kultury amerykańskiej egalitaryzmie. W porównaniu do przedstawicieli innych kultur, takich jak amerykańska, Polacy zwykle sprawiali wrażenie trochę ,sztywnych”, traktujących wszystko, w tym siebie, bardzo serio. To także się zmienia. Współczesne zachowania Polaków charakteryzuje "nonszalancja” (Marcjanik 2006) i "luz" (Ożóg 2005). Te nowe tendencje obserwowane w zachowaniach Polaków, szczególnie przedstawicieli młodego pokolenia, sprawiają, że coraz mniej miejsca w naszych relacjach z innymi na okazywanie szacunku. 
Trzecim, dominującym czynnikiem determinującym dynamikę interakcji w kulturze polskiej jest twarz. Polska twarz stanowi wypadkową wielu elementów:

1. czynników uwarunkowanych historycznie: Pomimo, że w kulturze polskiej liczy się współzależność i współpraca w grupie, a dbałość o wizerunek innych przeważa nad dbałością o wizerunek własny, w historii polskiej można dopatrzyć się wielu przykładów świadczących o indywidualizmie i niezależności Polaków (np. kultura szlachecka, okres złotej polskiej wolności, czy liberum veto), o ukochaniu przez nich wolności (np. walka o niepodległość, powstania listopadowe, styczniowe, czy warszawskie, czy działalność Solidarności).

2. czynników polityczno-społecznych: Transformacja polityczna i gospodarcza, jaka miała miejsce w Polsce po 1989 roku, wpłynęła na kulturę polską, obyczajowość i relacje społeczne, wywołując w nich zmiany, które z kolei wpłynęły na kształt twarzy polskiej. Zmiany te wykazują tendencje indywidualistyczne, co jak twierdzi Triandis (1995), jest charakterystyczne dla kultur krajów postkomunistycznych.

3. wpływów z zewnątrz: Po 1989 roku Polska stała się bardziej otwarta - przyczyniła się do tego nowowprowadzona gospodarka rynkowa, nasza przynależność do Unii Europejskiej, a co za tym idzie łatwiejsze kontakty oficjalne i prywatne $\mathrm{z}$ przedstawicielami innych kultur. Wszystko to zaowocowało przejęciem przez naszą kulturę wartości i wzorów zachowań specyficznych dla kultur Zachodu, a szczególnie kultury amerykańskiej. Wśród nich dominują dążenie do sukcesu, niezależność, indywidualizm i swoboda wyboru.

Polska twarz to nie tylko twarz jednostki, to także twarz grupy, rodziny, której dziecko może przynieść chlubę lub wstyd, co może prowadzić do utraty twarzy; czy grupy zawodowej - ataki na jej przedstawicieli wywołują często reakcje świadczące o poczuciu lojalności i chęci obrony dobrego imienia przedstawiciela tej grupy. W tych dwóch przypadkach, ujawnia się współzależny, kolektywistyczny charakter polskiej twarzy. Widoczny on jest również w umniejszaniu własnej wartości i własnych osiągnięć, podyktowanym skromnością; w dbałości o dobre samopoczucie rozmówcy i jego wizerunek, kosztem własnego wizerunku; czy w narzekaniu stosowanym jako strategia zacieśniania więzi z innymi ludźmi.

Natomiast to, co nowe w twarzy polskiej, świadczące o jej indywidualistycznym charakterze, to koncentrowanie się na sobie $\mathrm{i}$ wizerunku własnym $\mathrm{w}$ relacjach $\mathrm{z}$ innymi; podkreślanie swoich pozytywnych atrybutów i umniejszanie negatywnych; oraz otwarte mówienie o własnych sukcesach i osiągnięciach. 


\section{Wnioski}

Kluczem do zrozumienia charakteru dynamiki interakcyjnej jest kontekst kulturowy. W kulturze amerykańskiej dążenia uczestników interakcji społecznych podporządkowane są dwóm sprzecznym ze sobą pragnieniom, pragnieniu bliskości i akceptacji ze strony innych oraz pragnieniu dystansu i swobody działania. Spełnienie obu tych pragnień pozwala jednostce stworzyć wizerunek własny, a tym samym umożliwia jej komunikowanie się z innymi jednostkami zmagającymi się $\mathrm{z}$ tymi samymi pragnieniami i domagającymi się ich zaspokojenia. Tak więc, możliwość stworzenia pozytywnego wizerunku własnego - twarzy, która z jednej strony byłaby akceptowana przez innych, a z drugiej nie byłaby zagrożona przez ograniczanie swobody jednostki, decyduje o dynamice interakcyjnej w kulturze amerykańskiej.

Charakter interakcji społecznych w kulturze polskiej jest bardziej złożony. Wynika to po części ze złożoności samej kultury, po części z wielości czynników zewnętrznych wpływających na jej obecny charakter, o których wcześniej była mowa. Jako integralny element kultury polskiej i specyficznych dla niej zachowań międzyludzkich, polska uprzejmość została poddana gwałtownym przemianom. Proces ten wciąż trwa, podobnie jak kultura polska, polska uprzejmość znajduje się w fazie przejściowej.

Przemiany te, jednak, nie dotknęły w równym stopniu całej populacji Polaków. Tradycyjna uprzejmość normatywna dominuje wśród starszego pokolenia i wśród mniej wykształconych Polaków, i dla nich to szacunek wobec innych oraz honor są ważniejsze niż własna twarz. Uprzejmość strategiczna i dbałość o twarz, zarówno własną jak i twarz innego, przeważają wśród młodego pokolenia, które rozpoczęło dorosłe życie w ciągu ostatnich dwudziestu lat oraz wśród wykształconych Polaków. Wśród nich, wyrażanie szacunku wobec innych często brane jest pod uwagę tylko w wyjątkowych sytuacjach, lub traktowane jest instrumentalnie i służy osobistym celom jednostki.

\section{Przypisy}

\section{Informacje dodatkowe}

Tekst ten został po raz pierwszy opublikowany w roku $2013 \mathrm{w}$ tomie Słowo w kontekście pod redakcją Piotra Chruszczewskiego, Język a komunikacja 35. Kraków: Tertium; 51- 59. 


\section{Bibliografia}

Antas, Jolanta (2002) „Polskie zasady grzeczności”. [W:] Grzegorz Szpila (red.) Język trzeciego tysiaclecia II. Tom 1: Nowe oblicza komunikacji we współczesnej polszczyźnie. Kraków: Tertium; 347-363.

Bargiela-Chiappini, Francesca (2003) "Face and politeness: new (insights) for old (concepts)." Journal of Pragmatics 35; 1453-1469.

Bogdanowska-Jakubowska, Ewa (2010) FACE. An interdisciplinary perspective. Katowice.

Brown, Penelope, Stephen C. Levinson, (1987). Politeness. Some universals in language usage. Cambridge: Cambridge University Press.

Garcia, Wintilo (1996) "Respeto: a Mexican base for interpersonal relationships.” [W:] Wiliam, B. Gudykunst, Stella Ting-Toomey, Tsukasa Nishida (red.) Communication in personal relationships across cultures. Thousand Oaks: Calif. Sage; 122-136.

Goffman, Erving ([1967] 2006) Rytuat interakcyjny. [Interaction Ritual. Essays on Face-to-

Face Behavior. Oxford] (tłum.) Alina Szulżycka. Warszawa: Wydawnictwo Naukowe PWN.

Ide, Sachiko (1989) "Formal forms and discernment: two neglected aspects of universals of linguistic politeness." Multilingua 12; 7-11.

Kopaliński, Władysław [1985(1987)] Słownik mitów i tradycji kultury. Warszawa: Państwowy Instytut Wydawniczy.

Marcjanik, Małgorzata (2002) „Proces przewartościowania polskiej grzeczności językowej”.

[W:] Grzegorz Szpila (red.) Język trzeciego tysiaclecia II. Tom 1: Nowe oblicza komunikacji we współczesnej polszczyźnie. Kraków: Tertium; 391-396.

Marcjanik, Małgorzata (2006) „Przez grzeczność na skróty”. [W:] Małgorzata Marcjanik (red.) Retoryka codzienności. Zwyczaje językowe współczesnych Polaków. Warszawa; 230-238.

Ożóg, Kazimierz (2005) „Współczesny model polskiej grzeczności językowej”. [W:] Anna Dąbrowska, Alicja Nowakowska (red.) Język a kultura. Tom 17. Życzliwość i agresja w języku i kulturze. Wrocław: Wydawnictwo Uniwersytetu Wrocławskiego; 9-15.

Scollon, Ron, Suzanne Wong Scollon (2001) Intercultural communication. A discourse approach. Oxford: Blackwell.

Singelis, Theodore M., William J. Brown (1995) "Culture, self, and collectivist communication. Linking culture to individual behavior." Human communication research, Vol. 21, No. 3; 354-389.

Szymczak, Mieczysław (red.) Słownik języka polskiego PWN (1978-1981), Warszawa: PWN. 
Triandis, Harry C. (1995) Individualism and collectivism. Boulder, CO: Westview Press.

Usami, Mayumi (2006) "Discourse politeness theory and cross-cultural pragmatics." [W:]

Asako Yoshitomi, Tae Umino, Masashi Negishi (red.) Readings in second language pedagogy and second language acquisition: In Japanese context. Amsterdam: John Benjamins; 19-42.

Wierzbicka, Anna (1991) Cross-cultural pragmatics. Berlin, New York. 